\title{
A comparison of the effect of temperature on grapevine phenology between vineyards
}

$\equiv$ Wendy Cameron ${ }^{1}$, Paul R. Petrie ${ }^{2}$, E.W.R. Barlow ${ }^{1}$, Kate Howell ${ }^{1}$, Chelsea Jarvis ${ }^{3}$ and Sigfredo Fuentes ${ }^{1}$

${ }^{1}$ School of Agriculture and Food, Faculty of Veterinary and Agricultural Sciences,

The University of Melbourne, Parkville, Vic. 3010, Australia

${ }^{2}$ South Australian Research and Development Institute, Waite Research Precinct, Urrbrae, SA, 5064, Australia

${ }^{3}$ Centre for Applied Climate Sciences, Institute for Agriculture and the Environment,

University of Southern Queensland, Toowoomba, QLD, 4350, Australia

*corresponding author: wtinson@student.unimelb.edu.au

Associate editor: Daniel Molitor

\section{ABSTRACT}

The variability of grapevine phenological stages under climate change has been studied in many winegrowing regions, with many reporting an advancement of the major phenological stages, particularly flowering, veraison and harvest. This study aimed to compare these regional patterns to integrate our understanding of grapevine responses. Average daily January-March (JFM) mean temperatures were correlated with day of year budburst (DBUD) and average daily springtime March-May (MAM) maximum temperatures were correlated with day of year flowering (DFLO), day of year veraison (DVER) and day of year harvest (DHAR) for 17 vineyards and showed an advancement of the associated phenological stage with increased temperature for each index. There were significant differences between vineyard groups for the rate of advancement of DBUD, DVER and DHAR which suggests that the response of phenological stage to temperature is not linear and varies between cultivars. Only the interval between DBUD and DFLO showed a significant shortening as related to $\mathrm{MAM}_{\mathrm{Max}}$, suggesting that the advancement of grape maturity as related to increasing springtime maximum temperature is largely due to the shortening of the DBUD to DFLO interval.

\section{KEYWORDS}

budburst, flowering, grapevine, maturity, phenological stage, spring, temperature, veraison

Supplementary data can be downloaded through: https://oeno-one.eu/article/view/4599 


\section{INTRODUCTION}

Phenology is the study of the timing of recurring plant and animal life cycle stages and their relationship to climate (Schwartz, 2013). In viticulture, an understanding of the impact of climate on phenological stages is of significant interest in the investigation of the effects of climate change on grapevine growth (Chuine et al., 2004; Jones, 2003; Jones et al., 2005; van Leeuwen and Darriet, 2016). The ability to better predict phenological timing is important to enable more effective vineyard management, better short- and long-term planning (Caffarra and Eccel, 2010; Petrie and Sadras, 2008) and better use of resources.

The timing of phenological stages can vary depending on many factors, including the vineyard location, cultivar, management practices (Petrie et al., 2017; Webb et al., 2012), the season (Coombe, 1988), soil texture (Barbeau et al., 1998) and soil moisture content (Bonada et al., 2020). Notwithstanding, changes in the timing of the major grapevine phenological stages; budburst, flowering, veraison and maturity (Coombe, 1988), have been well documented with a general advancement in the timing of flowering, veraison and maturity having been shown over recent decades (Cameron et al., 2020; Jones and Davis, 2000; Petrie and Sadras, 2008; Tomasi et al., 2011; Webb et al., 2011), with concomitant warming trends (Jones et al., 2005) and these advancements are predicted to continue (Costa et al., 2019). Advances in budburst timing have been less clear. Tomasi et al. (2011) showed trends for advancement in flowering, veraison and harvest of 13 to 19 days, using data collected over a 45 -year period in Veneto, Italy but no trend for budburst. van Leeuwen et al. (2019) on the other hand showed an advancement of all four phenological stages, although the advancement of budburst was less than the other three stages. The lack of clear advancement for the budburst stage may be due to the competing effects of decreased winter chilling temperatures delaying budburst (Lavee and May, 1997) and warmer spring temperatures advancing budburst (Moncur et al., 1989). Several authors have indicated that grapevines have a low chill requirement (Dokoozlian, 1999; Fraga et al., 2019; Lavee and May, 1997; Mullins et al., 1992; Samish, 1954). Regardless, Kliewer and Soleimani (1972) demonstrated that for Thomson seedless, an increased chilling time did promote an earlier budburst. Cook et al. (2012) pointed out that not all plant species had shown advancement of phenological stages in response to warming temperatures and offered that this may be explained by the competing temperature effect on dormancy and budburst, but also other factors such as the influence of photoperiod (Nendel, 2010). Recent work by Ettinger et al. (2020) suggested that across many plant species, chilling may have more effect on budburst than the subsequent warming temperatures thus helping to explain the different responses of plants to warming temperatures. Further, budburst timing is also influenced by pruning timing (Martin and Dunn, 2000; Moran et al., 2017) and vine reserves (Williams et al., 1985) which may be being impacted by the timing of the previous advancing harvest (Hall et al., 2016).

While these trends of advancement in phenology have also been broadly linked with seasonal temperature (Bock et al., 2011; Malheiro et al., 2013; Tomasi et al., 2011) the specifics vary.

Bock et al. (2011) found that grapevines were most influenced by average maximum temperatures preceding the event, rather than mean or minimum temperatures, with rain and sunshine less important. They found climate variables using maximum temperatures of the preceding months gave significant regression coefficients with onset dates of various phenological stages, for example, budburst correlating with an average maximum temperature of February and April and flowering with maximum temperatures for April to July. Tomasi et al. (2011) found that average budburst dates were best correlated with mean temperatures during February and March and that flowering was best correlated with maximum temperatures from 10th April to 10th June. They found that measures of heat accumulation, such as growing degree days or the Huglin index, did not correlate any better with the phenological stages than these simpler measures of temperature (Tomasi et al., 2011). Calò et al. (1994) found that the average maximum temperature between budburst and flowering was most important for determining the flowering date. Malheiro et al. (2013) investigated a range of temperature variables and showed that for several cultivars, the maximum March-April temperature most influenced flowering timing, and veraison timing was related to March and April temperatures. Parker et al. (2011) developed strong models for flowering and veraison using mean temperatures across a range of European regions; Jarvis et al. (2017) found good correlations between maturity timing and 
the maximum springtime temperatures under Australian conditions and Koufos et al. (2020) showed that harvest dates (in Greece) were associated with maximum air temperatures during different months, depending on the timing of the grape ripening period.

The interval length between phenological stages has also been of interest because if there is a general advancement in the phenological stages other than budburst, one might expect a shortening of some or all of these intervals. A range of results have been reported. For example, Calò et al. (1994) showed a significant shortening of the budburst to flowering interval and corresponding increases in the average and maximum temperatures during this interval. The interval shortened until an average maximum temperature during the budburst to a flowering interval of about $29{ }^{\circ} \mathrm{C}$ was reached, after which point the interval length increased (Calò et al., 1994). Tomasi et al. (2011) found a shortening trend for the budburst to flowering interval over time. Duchêne and Schneider (2005) found that the flowering to veraison interval shortened about 1 day every 5 years and that the temperatures also increased during this period. Cameron et al. (2021) could not show any significant trends for the shortening of the veraison to maturity interval as related to springtime maximum temperatures and Jones and Davis (2000) and Tomasi et al. (2011) found shortening trends for the veraison to harvest interval over time.

While many studies have investigated the effect of temperature, and thus climate change, on grapevine phenology, these studies generally relate to individual grape-growing regions. Although some comparisons have been made (for example using modelling simulations (Leolini et al., 2020), comparisons between regions or vineyards using observed changes in phenology are rarely made. This study aimed to analyse previously published data from different vineyards and different climates to compare trends for the major phenological stages between these vineyards, to determine whether there were differences in the rate of change of advancement of these phenological stages between the different vineyards. An understanding of the comparison of phenological trends for a range of vineyards, with respect to the influence of temperature, would provide useful information to anticipate how future climate change will impact viticultural regions worldwide.

\section{MATERIALS AND METHODS}

\section{Selection of phenology data}

Meta-analysis principles were used to identify the sources of data used in this study. The Web of Science (WoS) database was used, and specific inclusion criteria were peer-reviewed literature published between 2000 and 2020, with all languages and document types considered. Each search was by "topic". The aim was to find publications that provided original (rather than modelled or simulated) day of year data for at least two of the major phenological stages (budburst, flowering, veraison and harvest) at a given vineyard, so comparisons could be made. The data was required to cover a period of at least 6 years and be in either a graphical or tabular form that enabled the extraction of the data from the paper for re-analysis. Only data for Vitis vinifera were included. A range of search terms were used, starting with broad terms, and narrowing down, as indicated in Table S1. The search process was repeated for some searches with the database Scopus, to check whether additional data sources were found. We also included any relevant papers that we were aware of or that were discovered using "snowballing" that were not identified by any of the searches.

As this study required data in graphs or tables to be present in each article, although many publications could be screened and discarded, based on the criteria, from the abstract, many publications needed the full text and, in some cases, the supplementary data to be looked through entirely to ascertain whether they contained suitable data. From the range of searches shown in Table S1, the relevant publications were selected using a PRISMA approach (Moher et al., 2009). The PRISMA approach involves a stepwise and systematic approach to the identification of possible relevant publications and then of narrowing these down through a screening and selection process, including recording the numbers of publications that have been involved at any stage of this process, to identify the final list of selected publications containing the required data sources (Figure S1).

Once the data sources had been identified, the data were digitised using the Graph Grabber software tool (https://www.quintessa.org/ software/downloads-and-demos/graph-grabber). 


\section{Temperature data}

CPC Global Temperature data (daily minimum and maximum) $\left(0.5^{\circ} \times 0.5^{\circ}\right)$ provided by the NOAA/OAR/ESRL PSL, Boulder, Colorado, USA, (https://psl.noaa.gov/) was accessed for the northern hemisphere locations. For the southern hemisphere (Australian) vineyards, temperature data were obtained from Scientific Information for Land Owners (SILO) (Jeffrey et al., 2001) which use datasets constructed from the Australian Bureau of Meteorology (BOM) observational data which are interpolated estimates taken from gridded datasets.

The climate grid reference nearest the vineyard location was selected but considering the altitude. In other words, if there were grid references on either side of a vineyard location, the grid reference with the most similar altitude was selected. The grid references for the weather data are detailed in Table S2. It is acknowledged that these nearest climate reference points may be at some distance from the vineyard, due to the grid size. In this study, we used the data commencing from 1979 , as this was the earliest year that the same method of obtaining continuous temperature data could be used across all studies.

\section{Calculation of temperature indices}

We aimed to make comparisons for the change in phenological stages between vineyard. The rate of change per year of the phenological stage was not considered useful as the different data sets were likely to cover different time periods. Therefore, we aimed to make comparisons in terms of a temperature index that was best suited to all the selected vineyards for each phenological stage. Ideally, the same temperature index could be used for at least two or more phenological stages so that comparisons between the stages at a given vineyard location could be made.

A range of temperature summations were screened to determine which were the most suitable for the analysis. For example, moving 3-month temperature summations, January-March (JFM), February-April (FMA), March-May (MAM) and so on to September-November (SON) were tested. Two-month temperature summations January-February (JF), February-March (FM), March-April (MA) and so on to OctoberNovember $(\mathrm{ON})$, were also tested, as were the temperature summations for individual months. The temperature summations were done using both the mean and the maximum daily temperatures.
Calculations for the 3-month temperature summations were, for example:

January-March maximum temperature $=\sum_{1 \mathrm{JAN}}^{31 \mathrm{MAR}}[\mathrm{Tmax} ; 0]$ (Equation 1)

Two-month summations were for example:

January-February mean temperature $=\sum_{1 \text { JAN }}^{28 \text { or } 29 \mathrm{FEB}}[$ Tmean; 0$]$ (Equation 2)

where $\mathrm{T}_{\mathrm{Max}}$ is the daily maximum temperature $\left({ }^{\circ} \mathrm{C}\right), \mathrm{T}_{\text {Mean }}$ is the daily mean temperature $\left({ }^{\circ} \mathrm{C}\right)$, and values of temperature $\leq 0$ are set to zero.

$\mathrm{R}^{2}$ was used to identify the best relationships between these temperature summations and the phenological stage, and the temperature summation with the highest $\mathrm{R}^{2}$ value was selected.

This temperature summation was then divided by the appropriate number of days for those months represented by the summation, to obtain the temperature index, for example:

$\mathrm{MAM}_{\text {Max }}=\sum_{1 \mathrm{MAR}}^{31 \mathrm{MAY}}[\mathrm{Tmax} ; 0] / 92$ (the number of days in March, April and May).

(Equation 3)

$\mathrm{JFM}_{\text {Mean }}=\sum_{1 \mathrm{JAN}}^{31 \mathrm{MAR}}[$ Tmean $; 0] / 90$ or 91 days । (the number of days in January, February and March depending on whether it was a leap year).

(Equation 4)

These temperatures indices were then used as the covariate in the subsequent statistical analyses.

Note that the equivalent of $\mathrm{JFM}_{\text {Mean }}$ temperature in the southern hemisphere is July-September $\left(\mathrm{JAS}_{\text {Mean }}\right)$. Any data shown, for example, JFM for a southern hemisphere vineyard, is actually the data for JAS. Because most of the vineyards in this study were northern hemisphere vineyards, to avoid confusion and enable comparisons to be made, the first 3 months of the growing season will be referred to as JFM, even for the southern hemisphere vineyards.

\section{Statistical analysis}

Statistical analysis was done using Minitab18 and Genstat software packages.

\subsection{Phenological stage changes at individual vineyards.}

Regression models were used to determine relationships between the selected temperature index and the phenological stages at individual 
vineyards; day of year budburst (DBUD), day of year flowering (DFLO), day of year veraison (DVER) and day of year harvest (DHAR) with the response: day of the year from the 1st Jan (or the 1st July for southern hemisphere vineyards) of the phenological stage; covariate: temperature index. Mixed models were used for vineyards where there was data for more than a single cultivar specified or two nearby vineyards with different cultivars. Where there were multiple cultivars and vineyards with identical temperature data, (for example Bock et al. (2011)), the mixed model response was DBUD, DFLO, DVER or DHAR; random factors: Cultivar, Vineyard (Cultivar nested in Vineyard) and Vintage Year; covariate: temperature index and where there were multiple cultivars at a single vineyard (Malheiro et al., 2013), the mixed models used were response: DBUD, DFLO, DVER or DHAR; random factors: Cultivar and Vintage Year; covariate: temperature index. The use of the mixed model which includes Vintage Year as a random factor takes into account and allows for the fact that the data for the different vineyards might cover different times periods as well as repeated observations within a vintage.

To determine whether there were differences in the rate of advancement for the different phenological stages at each vineyard, again, the exact model structure depended on the vineyard data. For most vineyards, general linear models were used with the response: day of the year of the phenological stage; factor: phenological stage; covariate: temperature index with an interaction term between phenological stage and the temperature index. In the cases where data for more than a single cultivar was specified, or two nearby vineyards with different cultivars, mixed models were used with response: day of the year of the phenological stage; random factors: Cultivar, Vineyard (Cultivar nested in Vineyard), Vintage Year (or Cultivar and Vintage Year and where the multiple cultivars were at one vineyard); fixed factor: phenological stage; covariate: temperature index and the same interaction factor between phenological stage and the temperature index. A value of $P<0.05$ for the interaction term between phenological stage and temperature index indicated that there was a significant difference in the rate of advancement of the different phenological stages at that vineyard.

\subsection{Differences between vineyard groups for the rate of change of each phenological stage}

Vineyards were grouped based on their average yearly mean temperature summation (Table 1). Differences between these grouped vineyards and their rates of change for each phenological stage were determined using similar model structures as above with the response: DBUD, DFLO, DVER or DHAR; random factors: Cultivar, Vineyard (Cultivar nested in Vineyard) and Vintage Year; fixed factor: Vineyard Group; covariate: temperature index and an interaction factor between Vineyard Group and the temperature index. A value of $P<0.05$ for the interaction term indicated a significant difference between the vineyard groups for the rate of advancement of that phenological stage. Pairwise comparisons of the slopes were made to investigate these differences.

The same method was used to determine whether there were differences in the advancement of each phenological stage for a single cultivar common to different vineyards with the response: DBUD, DFLO, DVER or DHAR; random factors: Vintage Year; fixed factor: Vineyard; covariate: temperature index and the interaction term between Vineyard and the temperature index.

Changes in the interval between each phenological stage were investigated using the same model structures as above but with the response being the interval length (days) between DBUD-DFLO, DFLO-DVER and DVER-DHAR.

\section{RESULTS}

\section{Selection of publications}

The WoS searches and search terms are shown in Table S1. While the initial search containing the term pheno* may have been finding sources with the word phenostage or phenophase as well as phenological stage, they were also finding many references related to phenolic composition in grapes and wine or phenotype. This search term was then refined to phenolog* in further searches (thus assuming most publications using the term phenostage would also use the term phenology or similar).

From these initial searches, a detailed look at the results from searches $\# 6, \# 7, \# 8, \# 9$, \#10, \#11, \#14 and \#15 (Table S1) was conducted using a PRISMA approach (Moher et al., 2009) (Figure S1).

12 studies were selected using the above criteria and method. Cameron et al. (2020) did not have the required data in their published paper but their original data from three vineyards were included. Two publications known to the authors were the highly cited study by Duchêne and Schneider (2005) which was found in \#14 and that by Garcia de Cortázar-Atauri et al. (2017) (\#8). 
Their data were repeated and updated in van Leeuwen et al. (2019) (\#8), and that publication was therefore selected. Two other publications were known to the authors. One by Stoll et al. (2011), primarily researching berry maturation and leaf area, and another study presented at a conference by Ghantous et al. (2018), had phenological data that met the criteria and were included in this study. The final fourteen papers considered were Bock et al. (2011), Caffarra and Eccel (2011), Cameron et al. (2020), De Rességuier et al. (2020), Dalla Marta et al. (2010), Ghantous et al. (2018), Jones and Davis (2000), Malheiro et al. (2013), Martinez de Toda and Ramos (2019), Ramos et al. (2015), Stoll et al. (2011), Tomasi et al. (2011), Urhausen et al. (2011) and van Leeuwen et al. (2019).
As a check, searches \#6, \#7, \#8 and \#14 were run in the Scopus database. As an example, search \#6 in Scopus yielded only 54 results (compared to 105 in WoS), eight of which were not in the Web of Science equivalent search. None of those eight results met the criteria. The same nine papers that met the criteria in the WoS search \#6 were found in this Scopus search. No additional papers that met the criteria were found in any of these additional Scopus searches.

\section{Summary of extracted data}

The 14 publications covered 17 vineyards in 8 countries: France, Germany, Italy, Lebanon, Portugal, Spain, Luxembourg and Australia (Table S2). Where specified by the authors,

TABLE 1. Data period, average mean July temperature (MJT), temperature summations and vineyard groupings for 17 vineyards in 8 countries.

\begin{tabular}{|c|c|c|c|c|c|c|}
\hline Vineyard & $\begin{array}{l}\text { Data } \\
\text { period }\end{array}$ & $\begin{array}{l}\text { Average } \\
\text { MJT } \\
\left({ }^{\circ} \mathrm{C}\right)\end{array}$ & $\begin{array}{c}\text { Average JFM } \\
\text { mean temperature } \\
\text { summation }\left({ }^{\circ} \mathrm{C}\right)\end{array}$ & $\begin{array}{l}\text { Average springtime } \\
\text { maximum temperature } \\
\text { summation }\left({ }^{\circ} \mathrm{C}\right)\end{array}$ & $\begin{array}{l}\text { Average yearly } \\
\text { mean temperature } \\
\text { summation }\left({ }^{\circ} \mathrm{C}\right)\end{array}$ & $\begin{array}{c}\text { Vineyard } \\
\text { Group }\end{array}$ \\
\hline Cembra, Italy & $1988-2007$ & 14.9 & 110.5 & 818.1 & 2436 & A \\
\hline Alsace, France & 1979-2018 & 18.2 & 319.9 & 1262.7 & 3577 & A \\
\hline Franconia, Germany & 1979-2010 & 18.8 & 314.4 & 1287.2 & 3650 & A \\
\hline Luxembourg & 1979-2005 & 18.8 & 376.1 & 1299.1 & 3790 & A \\
\hline Geisenheim, Germany & 1979-2009 & 19.6 & 393.8 & 1374.9 & 3958 & A \\
\hline Ribera del Duero, Spain & 2004-2013 & 21.3 & 488.8 & 1470.6 & 4344 & A \\
\hline Haro, Rioja, Spain & 2008-2018 & 20.7 & 622.2 & 1600.9 & 4690 & B \\
\hline Bordeaux, France & 1979-1997 & 20.7 & 652.8 & 1576.8 & 4701 & B \\
\hline Veneto, Italy & 1979-2009 & 23.7 & 504.1 & 1649.9 & 4950 & B \\
\hline Tuscany, Italy & 1979-2006 & 22.9 & 600.7 & 1616.8 & 4965 & B \\
\hline St Emilion, France & $2012-2018$ & 21.7 & 697.6 & 1721.8 & 5025 & $\mathrm{~B}$ \\
\hline Alfaro, Rioja, Spain & 2008-2018 & 24.1 & 773.8 & 1809.0 & 5518 & $\mathrm{~B}$ \\
\hline Milawa, Australia & 1999-2018 & 23.6 & 873.8 & 2005.5 & 5537 & $\mathrm{C}$ \\
\hline Heathcote, Australia & $2002-2018$ & 23.2 & 898.8 & 2039.6 & 5652 & $\mathrm{C}$ \\
\hline West Bekaa, Lebanon & 2009-2017 & 24.9 & 817.1 & 1892.5 & 6046 & $\mathrm{C}$ \\
\hline Lisbon, Portugal & 1990-2011 & 22.3 & 1119.5 & 1813.3 & 6116 & $\mathrm{C}$ \\
\hline Mystic Park, Australia & 2011-2018 & 25.0 & 1004.4 & 2225.1 & 6160 & $\mathrm{C}$ \\
\hline
\end{tabular}

Temperature data were obtained from worldwide daily maximum temperature data (CPC Global Temperature data) provided by the NOAA/OAR/ESRL PSL, Boulder, Colorado, USA.

MJT was $\sum_{1}^{31 \text { JUL or JAN }}$ mean $/ 31$.

Average JFM mean temperature summation was the average of the summation of daily mean temperatures for the months January, February, March (northern hemisphere) or July, August, September (southern hemisphere). Average springtime maximum temperature summation was the average of the summation of daily maximum temperatures for the spring months March, April, May (northern hemisphere) or September, October, November (southern hemisphere). Average yearly mean temperature summation was the average of the summation of the daily mean temperatures for the entire year. All averages were for the years shown in the data period. MJT; mean July temperature (northern hemisphere) mean January temperature (southern hemisphere). 
there was a diversity of methods used to systemise phenological stage identification. Although these differences would prevent any direct timing of phenological stage comparisons between publications from being made, they should not prevent comparisons of the change of phenological stage being made. Fourteen different cultivars were specified in these studies and in addition, there were data where results for two or many more cultivars were averaged. In general, different cultivars were located in different vineyards, which is not surprising given that different cultivars are generally suited to different climates (Fraga et al., 2015). Riesling was a common cultivar to four different vineyards, three in Europe and one in Australia, and Tempranillo was common to three vineyards, two in Rioja and one in Ribera del Duero.

As mentioned, we only used the data commencing from 1979 but several of the selected publications had data that extended prior to this (Bock et al., 2011; Dalla Marta et al., 2010; Jones and Davis, 2000; Tomasi et al., 2011; Urhausen et al., 2011; van Leeuwen et al., 2019).

The average yearly mean temperature summation varied across the selected vineyards, from $2436{ }^{\circ} \mathrm{C}$ for Cembra, Italy to $6160{ }^{\circ} \mathrm{C}$ for Mystic Park, Australia (Table 1). The temperatures obtained for Cembra in the mountainous area of Trentino, Italy seemed relatively low compared to the other vineyards. Caffarra and Eccel (2011) reported the mean temperature for the Cembra area for the years 2000-2009 as $11.1{ }^{\circ} \mathrm{C}$. The mean temperature obtained for the same period using the gridded data here was $7{ }^{\circ} \mathrm{C}$. This reflects the difficulties in using gridded weather data, rather than weather station data, particularly in areas where the terrain varies markedly over small distances (Schumacher et al., 2020), as it does in the Trentino region. Despite the similar altitudes of the vineyard where the phenology data were collected and the coordinates used for the Cembra weather data (Table S2), the gridded weather data seems to have a negative bias compared to the expected climate for this region. For this reason, it was decided to omit Cembra from the analyses where comparisons were being made between vineyard groups.

\section{Selection of a temperature index}

The best correlations for temperature and phenological stage were found using the 3-month temperature summations (Figure 1) rather than the 2-month and single month summations (Figures S2 and S3). In general, the mean temperatures for each temperature summation were better correlated with DBUD than maximum temperatures.

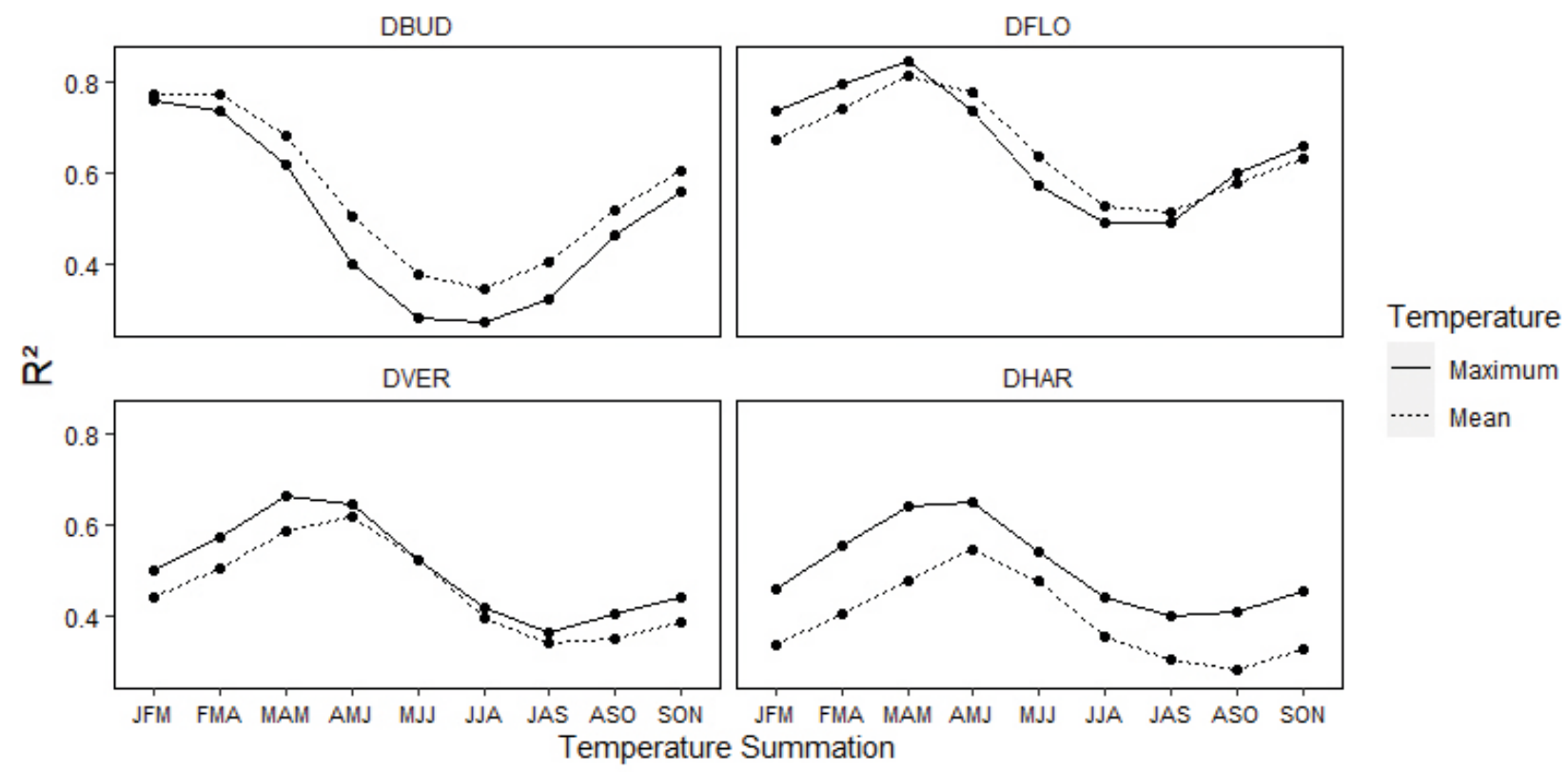

FIGURE 1: $R^{2}$ values for regression between each phenological stage DBUD, DFLO, DVER and DHAR and each 3-month temperature summation using mean and maximum daily temperatures, for all vineyards. JFM is the summation of mean (or maximum) daily temperature for January, February, and March and so on to SON for September, October, and November. This applies to the northern hemisphere vineyards. For the southern hemisphere vineyards, the results are presented using the equivalent results from the northern hemisphere (see text for details). DBUD, day of year budburst; DFLO, day of year flowering; DHAR, day of year harvest; DVER, day of year veraison. 
Mean and maximum temperatures gave similar correlations for DFLO varying with the actual months of the temperature summation. For DVER and DHAR, maximum temperatures were better correlated with the phenological stage than mean temperatures (Figures 1, S2 and S3).

These correlations (Figure 1) were also completed for each vineyard individually (Figures S4, S5, S6 and S7). While there were some differences between the vineyards, the overall pattern of correlation was similar, rather than the "all vineyards" correlations shown in Figure 1 simply averaging out otherwise disparate correlations from individual vineyards. The timing of each phenological stage was compared between the individual vineyards, along with the best 3-month temperature summation for each vineyard and phenological stage combination (Figures S8, S9, S10 and S11). As expected, the phenology is generally earlier in the warmer vineyards and in line with this, the best 3-month temperature summation, in general, became earlier. There were some unexpected results; for example, the best correlation for Ribera del Duero and DBUD was the August - October maximum temperature summation which is after DBUD had occurred. These graphs also need to be interpreted with caution as the results are from different time periods; for example, the warmest vineyard Mystic Park had the earliest phenological stage for DBUD, DFLO and DVER but this vineyard data come from a more recent and shorter time period (Table 1).

Notwithstanding, from these analyses we selected the January to March (JFM) mean temperature as the temperature index for the DBUD phenological stage analysis and the springtime March-May (MAM) maximum temperature as the temperature index for the DFLO, DVER and DHAR phenological stages analyses (see Equations 3 and 4).

\section{Phenology trends as a function of temperature indices}

The phenological stages budburst, flowering, veraison and harvest advanced as a function of their temperature index, $\mathrm{JFM}_{\text {Mean }}$ for DBUD, $\mathrm{MAM}_{\mathrm{Max}}$ for the other stages, at all vineyards (Table 2). For budburst, the advancement ranged from 0.02 (West Bekaa) to 14.44 (Bordeaux) days for every increase of $1{ }^{\circ} \mathrm{C}$ in the $\mathrm{JFM}_{\text {Mean }}$. These advancements for budburst were significant $(P<0.05)$ for 9 of the 14 vineyards. The budburst advancement at Bordeaux exceeded the next highest vineyard by a factor of almost two and it is worth pointing out that the Bordeaux budburst dates were derived using a temperature model (Table S2) rather than by observation, and the data do not show a normal distribution pattern.

For flowering, the advancement ranged from 1.81 days (Cembra) to 6.67 days (Franconia) for every increase in $1{ }^{\circ} \mathrm{C}$ in $\mathrm{MAM}_{\mathrm{Max}}$ and the Cembra trend was the only one that was not significant at the $P<0.05$ level. Veraison advanced from 2.55 days (Milawa) to 6.79 days (Alsace) for every increase of $1^{\circ} \mathrm{C}$ in $\mathrm{MAM}_{\mathrm{Max}}$ and the veraison trends were significant except for the Ribera del Duero, Milawa and Mystic Park vineyards. Harvest advancement trends ranged from 1.34 days (Tuscany) to 8.00 days (West Bekaa) for every $1{ }^{\circ} \mathrm{C}$ increase in $\mathrm{MAM}_{\mathrm{Max}}$ and were significant $(P<0.05)$ except for the Mystic Park, Rioja Alfaro, St Emilion and Tuscany vineyards (Table 2).

Differences in the rate of advancement of each phenological stage at each vineyard were observed (Table 2). To investigate whether these were significant, each vineyard was analysed independently in separate mixed models. This could only be done to compare the phenological stages with the same temperature index; DFLO, DVER and DHAR. The results from these models showed very similar slopes to the regression values obtained and showed that for three vineyards, Franconia, Tuscany and West Bekaa, there were significant differences between the rates of advancement of the DFLO, DVER and DHAR phenological stages as related to MAM $_{\text {Max }}$. The interaction terms between phenological stage and this temperature index were $P=0.022, P=0.004$ and $P=0.015$, respectively. These differences in the phenological stage advancement are indicated by the different letters for each of these stages at each of these vineyards (Table 2). In Franconia, DFLO and DVER advanced at a significantly great rate than DHAR; for Tuscany, DFLO advanced at a significantly greater rate than DHAR; yet for West Bekaa, DHAR advanced at a significantly greater rate than DFLO.

\section{Comparison of each phenological stage change between different vineyard groups}

The vineyards were grouped based on their average yearly mean temperature summation (Table 1). Although the same groups would have been obtained if average springtime maximum temperature summation or average JFM mean temperature summations were used (Table 1). As mentioned, Bordeaux DBUD data were obtained using a model, rather than by observation and 


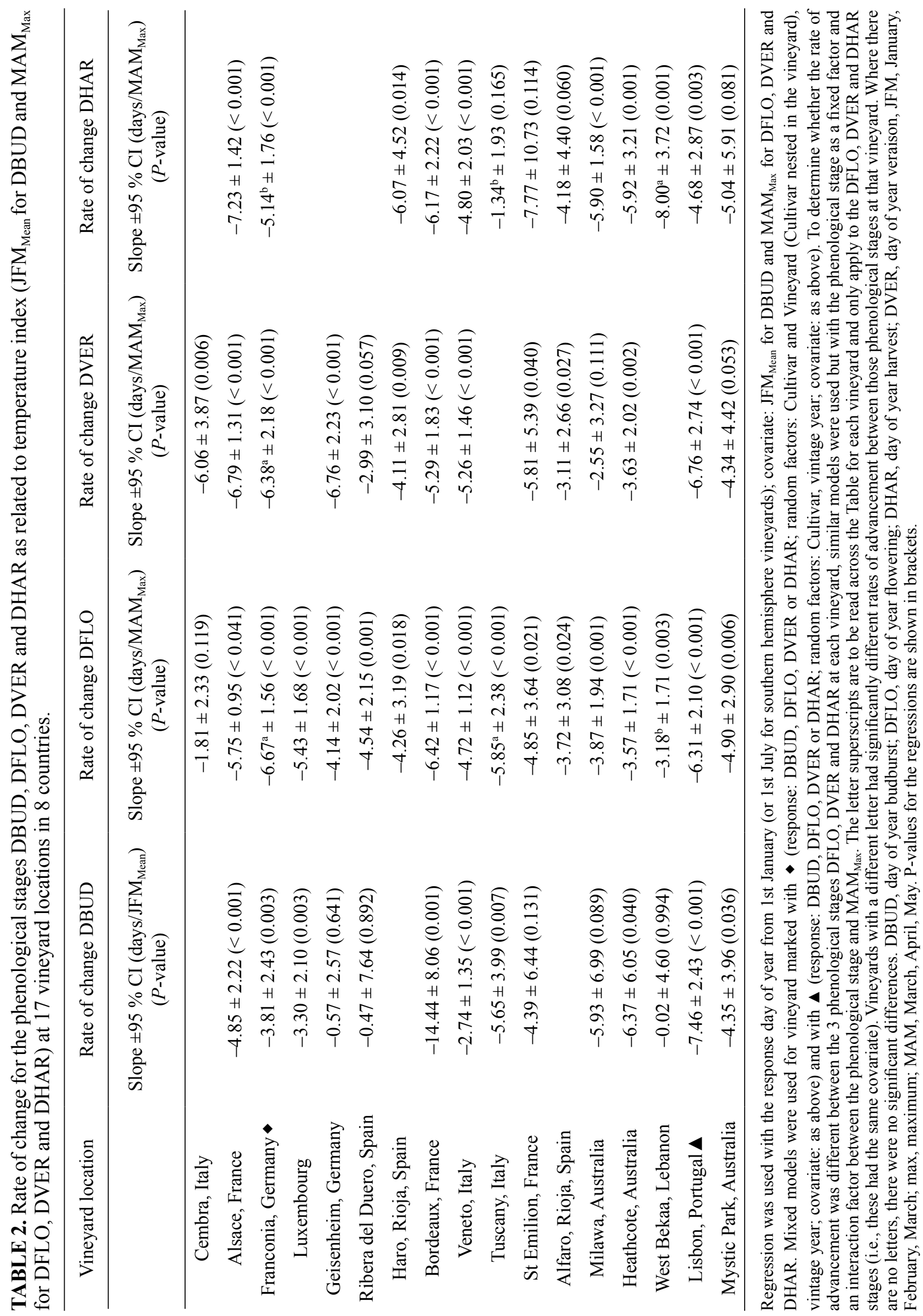


the rate of advancement was found to be almost twice that of the next highest rate (Table 2). For this reason, Bordeaux DBUD data were left out of these grouped vineyard analyses due to the concern that they may unreasonably skew the results. Cembra data (DFLO and DVER) as discussed previously was also left out of these vineyard group comparisons.

For the grouped vineyards, all the phenological stages advanced significantly as related to their respective temperature index (Figure 2). We found that for the budburst, veraison and harvest stages, there were significant differences in these rates of advancement between the different vineyard groups (Figure 2). There were no significant differences between the vineyard groups for the rate of advancement of flowering. This was indicated by the $P$-values for the interaction terms between the vineyard group and temperature index $(P<0.001$ for DBUD, $P=0.197$ for DFLO, $P 0.023$ for DVER and $P=0.026$ for DHAR).
For DBUD, the warmer vineyards, group C, advanced at a significantly greater rate of 6 days per $1{ }^{\circ} \mathrm{C}$ increase in $\mathrm{JFM}_{\text {Mean }}$ compared to the cooler groups A and B vineyards, which advanced at about 3 days per $1{ }^{\circ} \mathrm{C}$ increase in $\mathrm{JFM}_{\text {Mean }}$.

Although all vineyard groups showed an advancement of DFLO of about 5 days for every $1{ }^{\circ} \mathrm{C}$ increase in $\mathrm{MAM}_{\mathrm{Max}}$, there were no significant differences in the rate of DFLO advancement between the three vineyard groups. There were significant differences between the vineyard groups in the advancement of DVER with group A advancing significantly more than group $\mathrm{B}$, the difference is equivalent to about 1.5 days per $1{ }^{\circ} \mathrm{C}$ increase in $\mathrm{MAM}_{\mathrm{Max}}$. Group C's rate of advancement was intermediate to these. All vineyard groups showed an advancement of DHAR as related to $\mathrm{MAM}_{\mathrm{Max}}$ and similarly to DVER, group A advanced significantly more than group B and group C was intermediate (Figure 2).

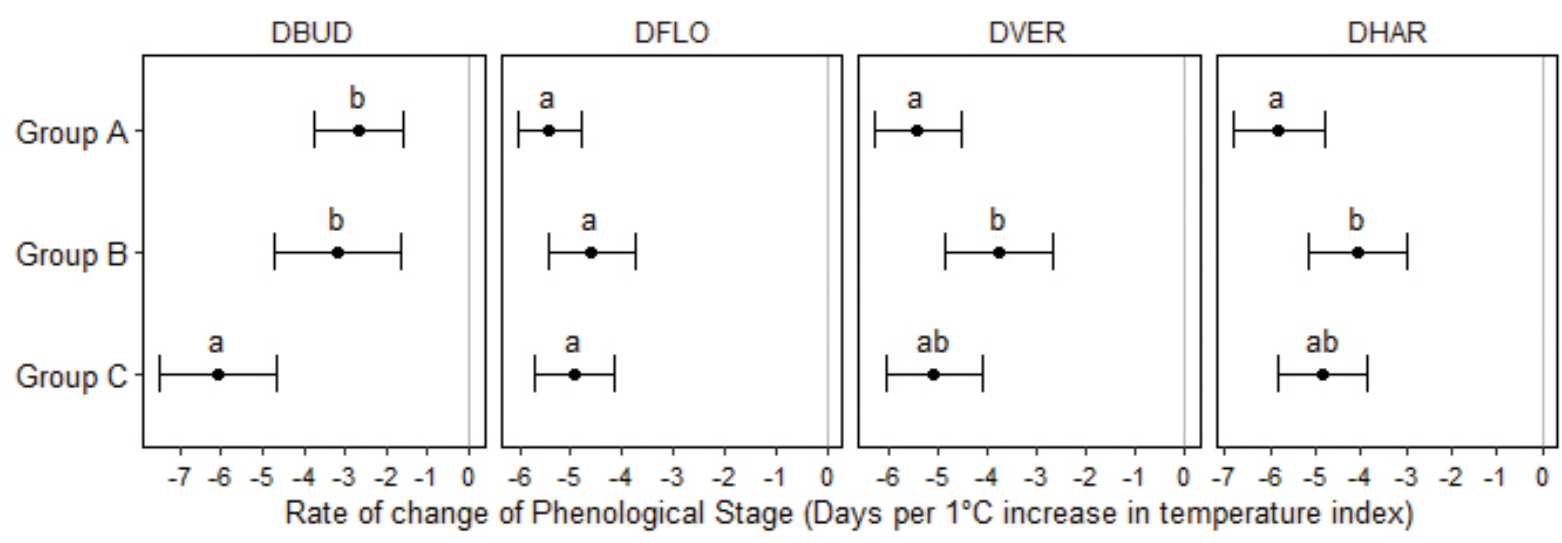

FIGURE 2. Mean rate of change of DBUD, DFLO, DVER and DHAR as related to the temperature index

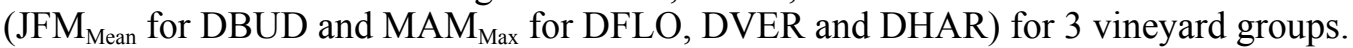

Mixed models were used with response: DBUD, DFLO, DVER or DHAR; random factors: Cultivar and Vineyard (Cultivar nested in Vineyard) and Vintage Year; fixed factor: Vineyard Group; covariate: temperature index as above with an interaction factor between Vineyard Group and the temperature index. The individual vineyard group rates of change for each phenological stage were separated using paired comparisons and vineyard groups with a different letter have significantly different rates of advancement for that phenological stage. Vineyards were grouped as per text (Table 1). The error bars show $95 \%$ confidence intervals. DBUD, day of year budburst; DFLO, day of year flowering; DHAR, day of year harvest; DVER, day of year veraison; JFM, January February March; MAM, March April May; Max, maximum.

\section{Comparisons of phenological stage timing changes for Riesling across different vineyards}

The cultivars varied between the vineyards (Table S2), so it was difficult to conclude whether these differences found for the rates of change for three of the four phenological stages were due to the cultivar or to the vineyard. To address this, the data for the cultivar Riesling, common to four vineyards, were analysed separately (Figure 3). This showed that there were significant differences in the rates of advancement for DFLO only, indicated by the $P$-value $=0.048$ for the interaction term between Vineyard and the temperature covariate, $\mathrm{MAM}_{\mathrm{Max}}$. Franconia and Alsace vineyards advanced DFLO about 1.5-2.0 days more than Geisenheim for every $1{ }^{\circ} \mathrm{C}$ increase in $\mathrm{MAM}_{\mathrm{Max}}$. For the other stages, the interaction term $P$ values were $P=0.260$ for DBUD, $P=0.109$ for DVER and $P=0.205$ for DHAR. 


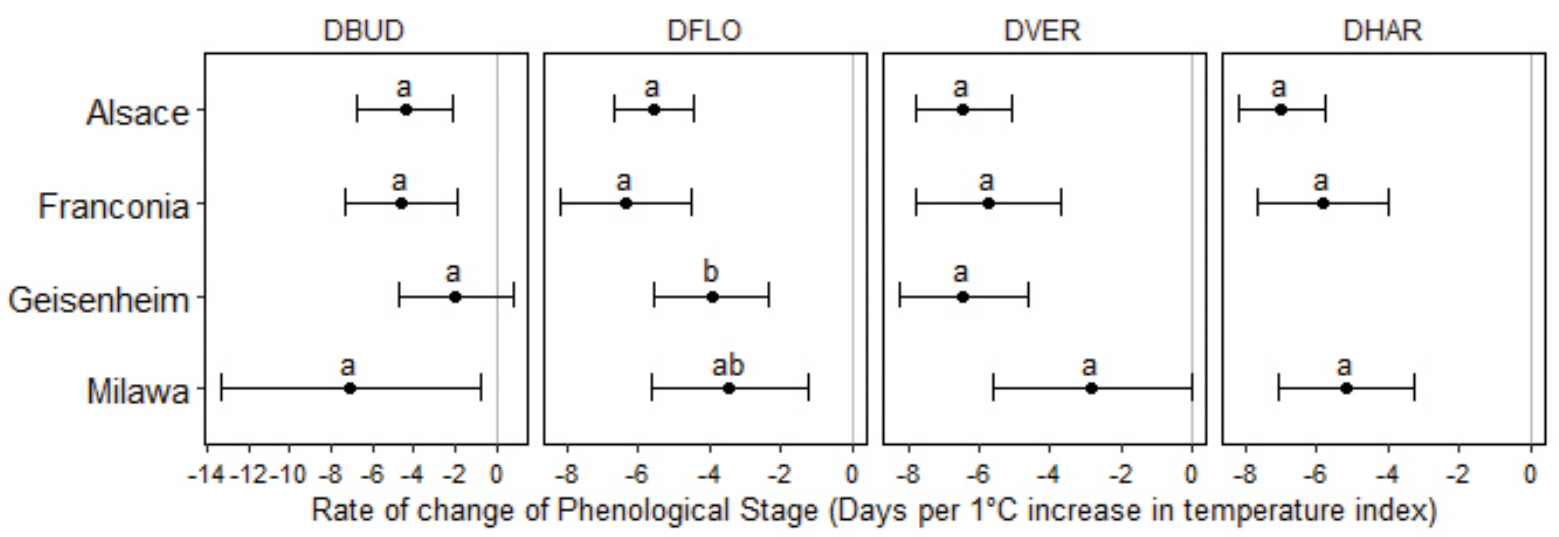

FIGURE 3. Rate of change of DBUD, DFLO, DVER and DHAR for Riesling at 4 vineyards as related to the temperature index, $\mathrm{JFM}_{\text {Mean }}$ for DBUD and $\mathrm{MAM}_{\mathrm{Max}}$ for DFLO, DVER and DHAR).

Mixed models were used: response: DBUD, DFLO, DVER or DHAR; random factor: Vintage Year; fixed factor: Vineyard; covariate: temperature index as above with an interaction factor between Vineyard and the temperature index. The individual vineyard rates of change of phenological stage were separated using paired comparisons and vineyards with a different letter have significantly different rates of change for that phenological stage. The error bars show $95 \%$ confidence intervals. DBUD, day of year budburst; DFLO, day of year flowering; DHAR, day of year harvest; DVER, day of year veraison; JFM, January February March; MAM, March April May. Max, Maximum.

In other words, where there was no significant difference found in the rate of advancement of DFLO between the vineyard groups, there was a significant difference found between the individual vineyards for Riesling for DFLO. Where there were differences found in the rate of advancement for DBUD, DVER and DHAR between the vineyard groups, there were no differences found between vineyards for Riesling for these stages.

The cultivar Tempranillo was also common to three vineyards, Ribera del Duero, Rioja Haro and Rioja Alfaro. Their data only shared the phenological stages DFLO and DVER and covered a shorter time period (Table 1). The same analyses as for Riesling were performed for Tempranillo and there were found to be no differences in the rate of change of DFLO nor DVER between the three vineyards for Tempranillo. The $P$-values for the interaction terms were $P=0.863$ for DFLO and $P=0.399$ for DVER.

\section{Comparison of interval trends between different vineyard groups}

Each phenological stage advanced as a function of its respective selected temperature index (Table 2) and the rate of advancement for DBUD, DVER and DHAR was significantly different between different vineyard groups (Figure 2). At three individual vineyards, there was a significant difference between the rate of advancement of DFLO, DVER and DHAR (Table 2). Following these observations, we investigated the rate of change of the intervals between the phenological stages.
To compare these intervals, we needed to use the same temperature index. We selected the $\mathrm{MAM}_{\mathrm{Max}}$ as this time period was within the interval between DBUD and DFLO (Figures S8 and S9), it correlated well with DBUD (Figure 1) and occurred before the subsequent intervals. Clearly, other temperature indexes might correlate better with the later intervals but for the purpose of comparison, we needed to use one temperature index and $\mathrm{MAM}_{\mathrm{Max}}$ seemed a good compromise.

Using the grouped vineyards; A, B and C (Table 1), we found a significant negative correlation between the interval length, DBUD-DFLO, and $\mathrm{MAM}_{\mathrm{Max}}$ for all vineyard groups (Figure 4). In other words, the interval between budburst and flowering became significantly shorter as the $\mathrm{MAM}_{\text {Max }}$ increased. The interval length, DBUD-DFLO, changed significantly differently between the three vineyard groups, indicated by a $P=0.009$ for the interaction term between Vineyard Group and $\mathrm{MAM}_{\text {Max }}$. Group C vineyards had decreased the interval length significantly more than group A. The change in interval length for Group B vineyards was not significantly different from Group A or Group C (Figure 4).

There was no significant change in the DFLO-DVER or DVER-DHAR interval length as related to $\mathrm{MAM}_{\text {Max }}$ (Figure 4). This is not surprising given that this temperature index occurs prior to these intervals and there may other temperature summations that correlated better with these intervals, however, the purpose here was comparison so the same temperature index 


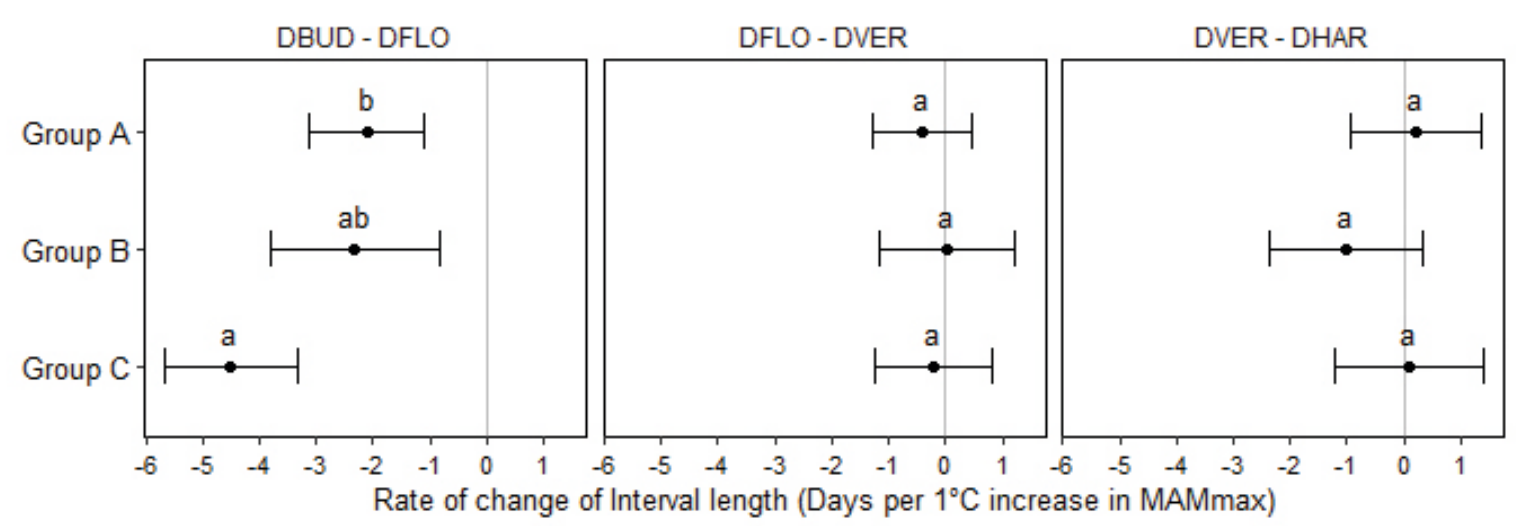

FIGURE 4. Rate of change of the interval (days) between DBUD-DFLO, DFLO-DVER and DVER-DHAR as related to MAMMax for 3 vineyard groups.

Mixed models were used: response: Interval (days) between the phenological stages DBUD, DFLO, DVER and DHAR; random factors: Cultivar, Vineyard (Cultivar nested in Vineyard) and Vintage Year; fixed factor: Vineyard Group; covariate: MAM $_{\text {Max }}$ with an interaction factor between Vineyard Group and $\mathrm{MAM}_{\mathrm{Max}}$. The individual rates of change of interval were separated using paired comparisons between vineyard groups with a different letter indicating significantly different rates of change for the interval. The error bars show $95 \%$ confidence intervals. DBUD, day of year budburst; DFLO, day of year flowering; DHAR, day of year harvest; DVER, day of year veraison. MAM $\mathrm{Max}_{\mathrm{x}}$, average daily March April May maximum temperature (northern hemisphere) and September October November (southern hemisphere). Max, Maximum.

was used for all three intervals. Nor were there any significant differences between the vineyard groups for the change of these interval lengths $(P$-value for the interaction term between Vineyard Group and $\mathrm{MAM}_{\text {Max }}$ were 0.799 and 0.285 , respectively). Although the phenological stages DFLO, DVER and DHAR advanced significantly as related to $\mathrm{MAM}_{\mathrm{Max}}$, these advancements did not result in any significant shortening of the intervals between these phenological stages, indicating they advanced at a similar rate.

\section{Comparisons of intervals for Riesling between different vineyards.}

The data for the cultivar Riesling were analysed in the same way. In contrast to the grouped vineyard results above, there were significant differences in the rate of change of the DFLO-DVER and DVER-DHAR intervals as related to $\mathrm{MAM}_{\mathrm{Max}}$, but not for the DBUD-DFLO interval (Figure 5). Only the Milawa DBUD-DFLO, Geisenheim DFLO-DVER and Milawa DVER-DHAR intervals had shortened significantly (Figure 5).

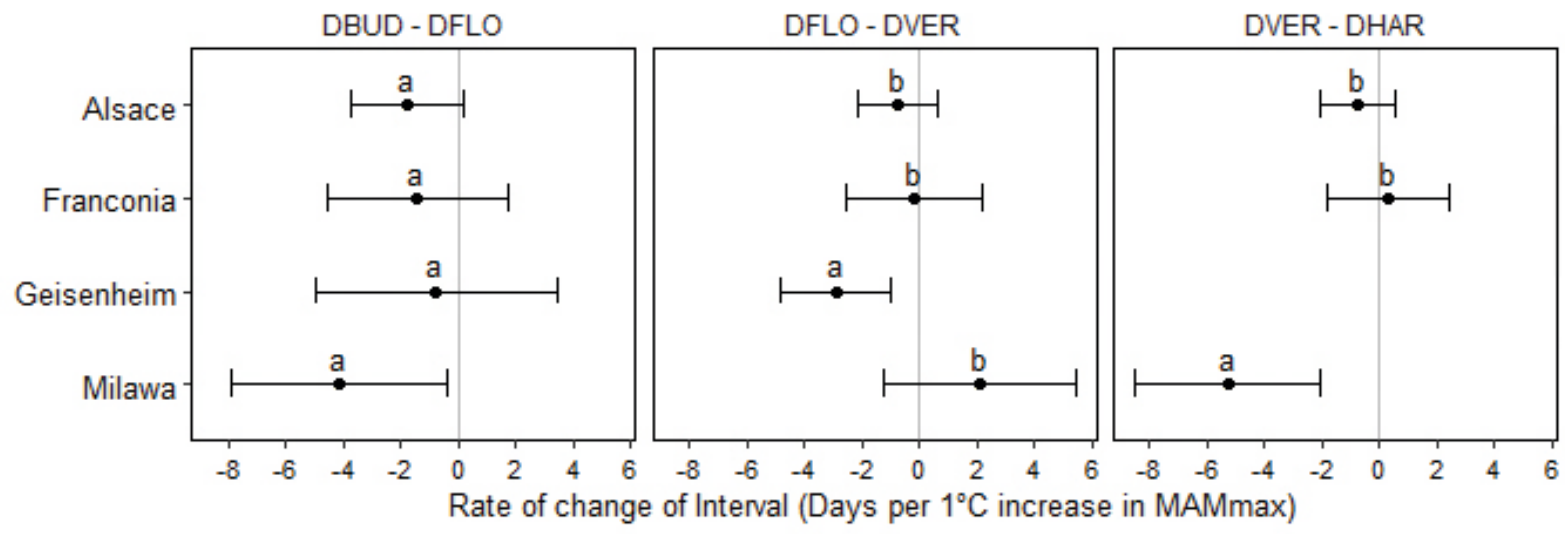

FIGURE 5. Rate of change of the interval (days) between DBUD-DFLO, DFLO-DVER and DVER-DHAR as a function of average daily MAM maximum for 4 Riesling vineyards.

Mixed models were used: response: Interval (days) between the phenological stages DBUD, DFLO, DVER and DHAR; random factors: Vintage Year; fixed factor: Vineyard; covariate: $\mathrm{MAM}_{\mathrm{Max}}$ with interaction factor between Vineyard and $\mathrm{MAM}_{\mathrm{Max}}$. The individual vineyard rates of change of interval were separated using paired comparisons and vineyards with a different letter had significantly different rates of change for the interval. The error bars show $95 \%$ confidence intervals. DBUD, day of year budburst; DFLO, day of year flowering; DHAR, day of year harvest; DVER, day of year veraison. MAM $_{\max }$, average daily March April May maximum temperature (northern hemisphere) and September October November (southern hemisphere). Max, Maximum. 
Tempranillo was also analysed for the DFLO to DVER interval and there was no significant shortening of the interval at any vineyard related to $\mathrm{MAM}_{\mathrm{Max}}$, nor was there a significant difference for the change in this interval between the vineyards $(P=0.267$ for the interaction term) .

The relationships between the phenological stage and the temperature summations were similar whether mean or maximum temperatures were used, with mean temperatures being better correlated with DBUD and maximum temperatures being slightly better correlated than mean temperatures for the stages DFLO, DVER and DHAR (Figure 1). Because of this similarity and the use of mean temperature in some phenological modelling (Parker et al., 2011), the analyses in this study were repeated using average daily MAM mean temperatures instead of average daily MAM maximum temperatures as the temperature index. The conclusions and trends in almost all cases were similar to the results shown above. The only notable differences were for DFLO trends which showed a greater advancement for each vineyard group and the differences between the three vineyard groups became significant (Group A slope $-7.28^{\mathrm{a}} \pm 0.85$, Group B slope $-5.75^{\mathrm{b}} \pm 1.06$ and Group C slope $-6.95^{\mathrm{ab}} \pm 1.08$ ). The other difference found when average daily MAM mean temperature was used as the temperature index was for the DVER trends for the Riesling only vineyards, where again the trends were generally larger and were significantly different (Alsace $-9.42^{\mathrm{a}} \pm 2.08$, Franconia $-8.04^{\mathrm{ab}} \pm 2.77$, Geisenheim $-8.45^{\mathrm{a}} \pm 1.18$ and Milawa $-1.72^{\mathrm{b}} \pm 4.52$ ).

\section{DISCUSSION}

Phenological data from fourteen previously published papers were identified using Web of Science searches and a PRISMA approach (Moher et al., 2009) and re-analysed to compare changes of phenological stages, as related to temperature, across vineyards with a range of climates.

We used CPC Global Temperature data but acknowledge that there are limitations when using gridded weather data. The weather data we used here had a grid of $0.5^{\circ} \times 0.5^{\circ}$, for which the dimensions vary depending on latitude, but which is approximately $55.5 \mathrm{~km}$ at the equator (approximately 3000 square kilometres). De Rességuier et al. (2020) showed that there was much spatial variability of temperature across an area of just 19,000 hectares ( $\sim 190$ square kilometres), especially for minimum temperature, of up to $10{ }^{\circ} \mathrm{C}$ on a given day.
We found that the temperature data obtained for the topographically variable Cembra, Trentino region was biased towards colder temperatures. Recent studies by Schumacher et al. (2020) highlighted some of the discrepancies between gridded weather data and weather station data, especially in mountainous areas. Regardless, the advantage of gridded weather data is that continuous and relatively finely spaced data is available and accessible for studies such as this.

Using this weather data, an extensive range of potential temperature summations were screened using the $\mathrm{R}^{2}$ value obtained for the regression between the temperature summation and the day of the year of the phenological stage. Previous research has found a range of temperature indices to be useful predictors of a given phenological stage, using varying time frames and both mean and maximum temperatures (Bock et al., 2011; Malheiro et al., 2013; Parker et al., 2011; Tomasi et al., 2011). Our results showed, not surprisingly, that the best temperature summation varied depending on vineyard location and the subsequent phenological stage occurrence at that vineyard (Figures S4 to S11). However, we aimed to choose the most appropriate temperature summation that could be used to make comparisons between the entire vineyard data set. Our analysis suggested that the 3-month temperature summation from January-March using the mean daily temperature summation $\left(\mathrm{JFM}_{\text {Mean }}\right)$ was best correlated with DBUD across this range of vineyards and that the 3-month summation for the springtime months March-May using maximum daily temperature summation $\left(\mathrm{MAM}_{\mathrm{Max}}\right)$ was best correlated with the other three phenological stages; DFLO, DVER and DHAR. These chosen temperature summations were not dissimilar to those found by others to correlate with these stages and that have already been mentioned previously in the Introduction section.

Analysing each phenological stage at each vineyard, we found that all stages advanced as related to their temperature index, with 45 of these 58 advancements being significant (Table 2). At three vineyards, Franconia, Tuscany and West Bekaa the rate of advancement of the phenological stages were found to be different between the stages DFLO, DVER and DHAR. At Franconia, the advancement of DFLO and DVER was significantly greater than that of DHAR and at Tuscany, the advancement of DFLO was significantly greater than that of DHAR. 
In contrast, the advancement of DHAR was significantly greater than that of DFLO at West Bekaa. This suggests that as the springtime maximum temperatures increase, the effect on these phenological stages is not uniform and may depend on the cultivar. The cultivars represented at these three vineyards are different, with white cultivars in Franconia, Sangiovese (red) in Tuscany and the late-ripening Cabernet-Sauvignon (red) in West Bekaa. The greater advancement of the earlier stages DFLO and DVER, than the DHAR stage, as related to $\mathrm{MAM}_{\mathrm{Max}}$, at the Franconia and Tuscany vineyards, points to a potential lengthening of the interval between DFLO and DHAR or DVER and DHAR, as related to $\mathrm{MAM}_{\mathrm{Max}}$, yet at the West Bekaa vineyard where DHAR advanced at a greater rate than DFLO, the interval between DFLO and DHAR would be expected to be more compressed. Understanding how the phenological stages will be impacted by a warming climate for a given cultivar or vineyard is important as it can inform vineyard management and adaptation strategies. For example, if the most pressing effect of the warming springtime temperatures was the advancement of harvest, strategies such as differential pruning, that have been found to delay harvest (Palliotto et al., 2017; Petrie et al., 2017), may be employed to ameliorate this. If on the other hand, the effect of the warming springtime temperatures is that DVER advances at a faster rate than DHAR, then an alternate strategy, such as manipulating leaf area, through leaf number, may be adopted as a mechanism to alter veraison timing (Parker et al., 2014).

When comparisons for each phenological stage were made, DBUD advanced at a greater rate for the warmer vineyard Group C than for Groups B and Group A (Figure 2). There were no significant differences for the advancement of DFLO between the vineyard groups when MAM $_{\text {Max }}$ was used as the temperature index, but as noted, when a different temperature index $\mathrm{MAM}_{\text {Mean }}$ was used, the advancements were larger and significantly different. For both DVER and DHAR, the cooler vineyards Group A advanced at a significantly greater rate than Group B, with Group C, the warmest vineyards being intermediate to these and not significantly different to either (Figure 2). In broad terms, if the effect of increasing temperature on the phenological stage was linear, one would expect the rate of advancement of a phenological stage, to be the same, regardless of the actual temperatures being experienced by the vine. That is, for each $1{ }^{\circ} \mathrm{C}$ increase in the average daily mean or maximum temperature, the rate of advancement would be the same regardless of whether the increase was from $10{ }^{\circ} \mathrm{C}$ to $1{ }^{\circ} \mathrm{C}$ or from $20^{\circ} \mathrm{C}$ to $21^{\circ} \mathrm{C}$. It is noted that there are different cultivars in each vineyard group and even if each cultivar had a linear response for the relationship between phenological stage and temperature, the rate of the response may be different for each cultivar. Therefore, a comparison of response between different vineyard groups with different cultivars could give different rates, even with a linear response for each cultivar.

The significantly different rates of advancement for a phenological stage between the different vineyard groups found here could also be explained by a nonlinear response between the phenological stage and temperature. For the DVER and DHAR stages, the advancement was greater for the cooler Group A vineyards than the warmer Group B vineyards. The cooler Group A vineyards could be responding in the early linear part of the response curve, but the Group B vineyards could be occurring in the flattening part of the response curve where the rate of change has begun to slow and where they might be outside the optimum temperature range and no longer respond by advancing the day of the year for that phenological stage at the same rate (Garcia de Cortazar Atauri et al., 2010). The intermediate result for Group $\mathrm{C}$ vineyards did not appear to fit this explanation but the cultivars in each group are different, and it may be that the response curves are displaced differently along the axis for each cultivar and each response curve shape is different for each cultivar.

For the Riesling results, although the differences in advancement for DVER and DHAR were not significant, the warmer Milawa vineyard did have a slower rate of advancement for these stages than the other three cooler vineyards, which is consistent with this suggestion of a nonlinear response to temperature, with the warmer vineyards responding at a slower rate, due to the higher temperatures (Morales-Castilla et al., 2020). It should also be noted that interpretation of the DHAR stage is difficult because DHAR is not a true phenological stage (Menzel et al., 2006) and its method of determination varied across the publications used in this study (Table S2).

Both linear and nonlinear models have been used to describe the response of the phenological stage to temperature (Cuccia et al., 2014; Molitor et al., 2020), and even an apparent linear response may become nonlinear at further increased temperatures (Morales-Castilla et al., 2020), 
not thus far experienced in a given data set. Cameron et al. (2020) found that both Shiraz and Tempranillo advanced their day of year maturity more rapidly with increasing maximum springtime temperatures at a cooler vineyard than at a warmer vineyard, consistent with a nonlinear response, whereas there were no differences for this advancement for Dolcetto or Cabernet-Sauvignon at different vineyards. They also found that different cultivars at the same vineyard advanced their maturity date at different rates. They used a common day of year maturity definition in their work so the potential difficulties with using DHAR were avoided. Their work supports the idea that the response curve between the phenological stage and springtime temperature may be displaced differently along a given axis and have a different shape for individual cultivars (Garcia de Cortazar Atauri et al., 2010).

DFLO advanced for all vineyards and there were no significant differences between the vineyard groups for the rate of advancement of this stage, suggesting a linear response between DFLO and spring maximum temperatures for these cultivars at these vineyards, although as noted previously, when a different temperature index was used $\left(\mathrm{MAM}_{\mathrm{Mean}}\right)$, the Group B vineyards did advance significantly less than the cooler Group A vineyards.

For the DBUD stage, the cooler Group A and $B$ vineyards were found to have advanced at a significantly lower rate than the warmer Groups C vineyards. Again, if the phenological stage response to temperature was linear, in general, one would expect these rates of advancement to be the same. As discussed above, the different cultivars in the vineyard groups complicate the interpretation, but the results found here (Figure 2 ), could be consistent with a different linear response for different cultivars, or a nonlinear response such that at the lower temperatures experienced by the Group A and B vineyards, the rate of change of DBUD was slower than the subsequent rate of change of DBUD at the warmer vineyards (imagine a response curve for DBUD and temperature being an upside-down sigmoidal curve). This suggestion is consistent with that by Ettinger et al. (2020) who elaborated that although temperature and DBUD relationships were often estimated using a linear relationship, it may be that a nonlinear relationship was better able to describe this complex relationship between DBUD and temperature, which is influenced by two temperature effects, winter chilling and spring warming as well as photoperiod (Ettinger et al., 2020; Flynn and Wolkovich, 2018). It may be for the warmer Group C vineyards, with the higher rate of DBUD advancement, that the delaying effect of less winter chilling is being overridden more by the advancing effect of warming spring temperatures, than for the other two vineyard groups. This supports Martinez-Lüscher et al. (2016) who showed that budburst date was influenced less by the competing effects on its timing of the temperature of the chilling period than the temperature during the warming period in their Croatian study. With further climate change, there could be advancement, delay or no change in budburst timing depending on the balance of the effects of decreased winter chilling (and its possible delaying effect on budburst) and increased spring warming (and the expected advancement of budburst) (Yonghuo et al., 2012).

Only the DBUD-DFLO interval showed a significant shortening as related to springtime maximum temperatures and significant differences between the three vineyard groups (Figure 4). For the other intervals, there was no significant change in interval length nor significant differences between the change in interval length between the vineyard groups as related to $\mathrm{MAM}_{\mathrm{Max}}$. This is not surprising as these later intervals occur well past these springtime months and it would be expected that later temperature period summations would be better correlated with these later intervals. However, having identified significant advancements in the three phenological stages DFLO, DVER and DHAR as related to MAM Max $_{\text {, }}$ we wanted to try to relate these advancements to changes in interval length, so it was instructive to use the same temperature index, MAM $_{\mathrm{Max}}$, for the interval comparison. The trends seen here for the intervals between phenological stages indicate that advancement in grape maturity as a function of increasing springtime maximum temperatures is largely due to a shortening of the DBUD-DFLO interval, not changes in the later DFLO-DVER or DVER-DHAR interval length. Again, it needs to be remembered that when discussing the DVER-DHAR interval, that DHAR is false phenophase (Menzel et al., 2006) and that the fact that its timing can be influenced by management decisions needs to be taken into consideration when interpreting these results. In some cases the warmer weather may have been taken advantage of to allow grapes to ripen more before harvest, resulting in an overall lengthening of the growing season (Jones and Davis, 2000) while in other cases the earlier maturing fruit would have triggered harvest (Petrie and Sadras, 2008). 
Using a day of year maturity instead of harvest date, Cameron et al. (2021) found no significant shortening of the veraison to maturity interval for a range of cultivars at four vineyards as related to springtime maximum temperatures.

When these analyses in this study were repeated for a single cultivar, Riesling, at four vineyards the results contrasted from the grouped vineyards. Although there was a significant advancement for almost all the phenological stages at each vineyard (Geisenheim DBUD and Milawa DVER being the exceptions (Figure 3)) the only significant difference found between the Riesling vineyards was for the DFLO phenological stage, in complete contrast to the situation for the grouped vineyards where the only stage that did not show a significant difference between vineyard groups was the DFLO stage (Figure 2). For the interval analysis, again, the Riesling results contrasted to the grouped vineyards. For the Riesling cultivar (Figure 5), there were significant differences between the vineyards for the change in interval length for the DFLO-DVER and DVER -DHAR interval, where there were no differences for these intervals between the vineyard groups. Of course, one analysis is looking at the differences between vineyard groups for different cultivars and the other is looking at the difference between individual vineyards and a single cultivar, but neither were there any significant differences between the Riesling vineyard groups for the rate of advancement of any of the phenological stages nor the interval length for Riesling (results not shown). There are likely to be clonal and/ or rootstock differences for the Riesling, and there are other impacts on phenological timing, such as those on budburst timing such as soil moisture (Bonada et al., 2020), pruning timing (Moran et al., 2017) or carbohydrate reserves (Williams et al., 1985). However, these results suggest that the vineyard group differences found here are due to the different cultivar mix between the different vineyard groups. It suggests that individual cultivars behave differently in their response to warming temperatures.

The length of time between phenological stages is important, as significant changes are occurring in the plant during these times (Duchêne and Schneider, 2005). Not only may the earlier timing of grape harvest in a warmer period have implications for the grape composition and therefore quality (Coombe, 1987; Jackson and Lombard, 1993), with major changes in grape composition, such as sugars, anthocyanins, flavour compounds and tannins occurring between veraison and harvest, (Bindon et al., 2013; Keller, 2010), any change in the interval length between DVER and DHAR could also have implications for the development and accumulation of grape components and thus the physiological composition of the grape now and with further climate change.

Further understanding of how individual cultivars at individual vineyards are responding to increased temperatures will help to improve models to predict the timing of the phenological stages under different climate change scenarios. This will be required to enable vineyard managers to adopt strategies to manage these changes and to inform them of what cultivars might be planted in future to cope with climate change.

\section{CONCLUSION}

This study found that both mean and maximum temperatures provided useful temperature indices for correlations between the timing of the major phenological stages and temperature. DBUD correlated well with JFM mean temperatures for this wide range of vineyards and springtime MAM maximum temperatures correlated well with flowering, veraison and maturity timing. There was an advancement of all phenological stages with increases in their temperature index, but this occurs at different rates for different vineyard groups with different cultivars. For different vineyards with the same cultivar, Riesling, there were significantly different rates of advancement between vineyards for the phenological stage DFLO. There was a significant shortening of the interval between DBUD and DFLO for all three vineyard groups as related to springtime maximum temperatures, with the warmer Group C vineyards, the interval decreased at a significantly greater rate than the Group A vineyards. There was no evidence for a change in the interval lengths DFLO-DVER nor DVER-DHAR as related to springtime maximum temperatures, therefore the advancement of DHAR as related to springtime maximum temperature would seem to be largely the result of a decrease in the interval length between DBUD and DFLO.

The different results obtained for a single cultivar, Riesling, suggest that the differences found between vineyard groups are due to the cultivar differences between the vineyard groups and that each cultivar is responding differently to the increased temperatures. These results suggest that warming temperatures will affect cultivars and therefore vineyards and regions differently and 
that responses to climate change by viticulturists will need to be tailored to their individual situation. Insights into the response of grapevine phenology at both a vineyard level and for different cultivars will further our ability to adapt and help to identify techniques to delay or ameliorate these climateinduced changes.

Acknowledgements: This work has been supported by an Australian Government Research Training Program Scholarship provided by the Australian Commonwealth Government and The University of Melbourne. Acknowledgements go to the Brown Family Wine Group and staff who have permitted access to and helped retrieve the historical data for this research. Acknowledgements also go to Professor Graham Hepworth of the Statistical Consulting Centre at the University of Melbourne for valuable input and advice. We would also like to acknowledge the authors of the publications from which the data for this study were collected.

\section{REFERENCES}

Barbeau, G., Asselin, C., \& Morlat, R. (1998). Estimation du potential viticole des terroirs en Val de Loire selon un indice de précocité du cycle de la vigne. Bulletin de l'OIV, 805-806, 247-262.

Bindon, K., Varela, C., Kennedy, J., Holt, H., \& Herderich, M. (2013). Relationships between harvest time and wine composition in Vitis vinifera $\mathrm{L}$. cv. Cabernet-Sauvignon 1. Grape and wine chemistry. Food Chemistry, 138(2-3), 1696-1705. https://doi.org/ https://doi.org/10.1016/j.foodchem.2012.09.146

Bock, A., Sparks, T., Estrella, N., \& Menzel, A. (2011). Changes in the phenology and composition of wine from Franconia, Germany. Climate Research, 50(1), 69-81. http://www.int-res.com/abstracts/cr/v50/n1/ p69-81/

Bonada, M., Edwards, E. J., McCarthy, M. G., Sepúlveda, G. C., \& Petrie, P. R. (2020). Impact of low rainfall during dormancy on vine productivity and development. Australian Journal of Grape and Wine Research, 26(4), 325-342. https://doi.org/doi:10.1111/ ajgw. 12445

Caffarra, A., \& Eccel, E. (2010). Increasing the robustness of phenological models for Vitis vinifera $\mathrm{cv}$. Chardonnay. International Journal of Biometeorology, 54(3), 255-267. https://doi.org/10.1007/s00484-0090277-5

Caffarra, A., \& Eccel, E. (2011). Projecting the impacts of climate change on the phenology of grapevine in a mountain area [Article]. Australian Journal of Grape \& Wine Research, 17(1), 52-61. https://doi.org/10.1111/ j.1755-0238.2010.00118.x
Calò, A., Tomasi, D., Costacurta, A., Biscaro, S., \& Aldighieri, R. (1994). The effect of temperature thresholds on grapevine (Vitis sp.) bloom: an interpretative model. Riv. Vitic. Enol, 1, 3-14.

Cameron, W., Petrie, P., Barlow, E. W. R., Patrick, C. J., Howell, K., \& Fuentes, S. (2021). Is advancement of grapevine maturity explained by an increase in the rate of ripening or advancement of veraison? Australian Journal of Grape and Wine Research. https://doi.org/ https://doi.org/10.1111/ajgw.12481

Cameron, W., Petrie, P. R., Barlow, E. W. R., Patrick, C. J., Howell, K., \& Fuentes, S. (2020). Advancement of grape maturity: comparisons between contrasting cultivars and regions. Australian Journal of Grape and Wine Research, 26(1), 53-67. https://doi. org/https://doi.org/10.111/ajgwr.12414

Chuine, I., Yiou, P., Viovy, N., Seguin, B., Daux, V., \& Ladurie, E. L. R. (2004). Grape ripening as a past climate indicator. Nature, 432, 289. http://dx.doi. org $/ 10.1038 / 432289$ a

Cook, B. I., Wolkovich, E. M., \& Parmesan, C. (2012). Divergent responses to spring and winter warming drive community level flowering trends. Proceedings National Academy of Science USA, 109(23), 90009005. https://doi.org/10.1073/pnas.1118364109

Coombe, B. G. (1987). Influence of temperature on composition and quality of grapes. ISHS Acta Horticulturae, 206, 25-35.

Coombe, B. G. (1988). Grape Phenology. In B. G. Coombe \& P. R. Dry (Eds.), Viticulture Volume 1 Resources in Australia (Vol. 1, pp. 139-153). Australian Industrial Publishers Pty Ltd.

Costa, R., Fraga, H., Fonseca, A., García de Cortázar-Atauri, I. A., Val, M. C., Carlos, C., Reis, S., \& Santos, J. o. A. (2019). Grapevine Phenology of cv. Touriga Franca and Touriga Nacional in the Douro Wine Region: Modelling and Climate Change Projections [Journal Article]. Agronomy, 9(4). https:// doi.org/10.3390/agronomy9040210

Cuccia, C., Bois, B., Richard, Y., Parker, A., García de Cortázar-Atauri, I., van Leeuwen, C., \& Castel, T. (2014). Phenological model performance to warmer conditions: application to Pinot noir in Burgundy. - OENO One, 48(3), 169-178. https://doi. org/https://doi.org/10.20870/oeno-one.2014.48.3.1572

Dalla Marta, A., Grifoni, D., Mancini, M., Storchi, P., Zipoli, G., \& Orlandini, S. (2010). Analysis of the relationships between climate variability and grapevine phenology in the Nobile di Montepulciano wine production area. Journal of Agricultural Science, 148, 657-666. https://doi.org/10.1017/S0021859610000432

De Rességuier, L., Sevérine, M., Le Roux, R., Petitjean, T., Quénol, H., \& Van Leeuwen, C. (2020). Temperature variability at local scale in the Bordeaux area. Relations with environmental factors and impact on vine phenology. Frontiers in Plant Science, 11, 1-20. https://doi.org/10.3389/fpls.2020.00515 
Dokoozlian, N. K. (1999). Chilling temperature and duration interact on the budbreak of Perlette grapevine cuttings. HortScience, 34, 1054-1056. https://doi. org/10.21273/HORTSCI.34.6.1

Duchêne, E. H., \& Schneider, C. (2005). Grapevine and climatic changes: a glance at the situation in Alsace. Agronomy for Sustainable Development, 25, 93-99. https://doi.org/10.1051/agro:2004057

Ettinger, A. K., Chamberlain, C. J., Morales-Castilla, I., Buonaiuto, D. M., Flynn, D. F. B., Savas, T., Samaha, J. A., \& Wolkovich, E. M. (2020). Winter temperatures predominate spring phenological responses to warming. Nature Climate Change, 10, 11371142. https://doi.org/10.1038/s41558-020-00917-3

Flynn, D. F. B., \& Wolkovich, E. M. (2018). Temperature and photoperiod drive during spring phenology across all species in a temperate forest community. New Phytologist, 2019, 1353-1362. https://doi.org/10.1111/ nph.15232

Fraga, H., Costa, R., Moutinho-Pereira, J., Correia, C. M., Dinis, L.-T., Gonçalves, I., Silvestre, J., Eiras-Dias, J., Malheiro, A. C., \& Santos, J. A. (2015). Modeling Phenology, Water Status, and Yield Components of Three Portuguese Grapevines Using the STICS Crop Model [10.5344/ajev.2015.15031]. American Journal of Enology and Viticulture, 66(4), 482. http://www.ajevonline.org/content/66/4/482. abstract

Fraga, H., Pinot, J. G., \& Santos, J. A. (2019). Climate change projections for chilling and heat forcing conditions in European vineyards and olive orchards: a multi-model assessment. Climatic Change, 152(1), 179-193. https://doi.org/10.1007/s10584-018-2337-5

Garcia de Cortázar-Atauri, I., Duchêne, E., Destrac-Irvine, A., Barbeau, G., De Rességuier, L., Lacombe, L., PArker, A., Saurin, N., \& Van Leeuwen, C. (2017). Grapevine phenology in France: from past observations to future evolutions in the context of climate change. OENO One, 51(2), 115-126. https://doi.org/https://doi.org/10.20870/oenoone.2016.0.0.1622

Garcia de Cortazar Atauri, I., Chuine, I., Donatelli, M., Parker, A. K., \& van Leeuwen, C. (2010). A curvilinear process-based phenological model to study impacts of climatic change on grapevine (Vitis vinifera L.). Proceedings of Agro 2010: the 11th ESA Congress, Montpellier, France,

Ghantous, G., Popov, K. T., Assadi, F., \& Sassine, Y. N. (2018). A study on the phenological stages of the variety Cabernet-Sauvignon under the effect of climate change grown in the region of West Bekaa, Lebanon. IX International Agricultural Symposium "Agrosym 2018", 4-7 October 2018, Jahorina.

Hall, A., Mathews, A. J., \& Holzapfel, B. P. (2016). Potential effect of atmospheric warming on grapevine phenology and post-harvest heat accumulation across a range of climates. International Journal of Biometeorology, 60(9), 1405-1422. https://doi. org/10.1007/s00484-016-1133-z
Jackson, D. I., \& Lombard, P. B. (1993). Environmental and Management Practices Affecting Grape Composition and Wine Quality - A Review. American Journal of Enology and Viticulture, 44(4), 409. http:// www.ajevonline.org/content/44/4/409.abstract

Jarvis, C., Barlow, E., Darbyshire, R., Eckard, R., \& Goodwin, I. (2017). Relationship between viticultural climatic indices and grape maturity in Australia. International Journal of Biometeorology, 61(10), 18491862. https://doi.org/10.1007/s00484-017-1370-9

Jeffrey, S. J., Carter, J. O., Moodie, K. B., \& Beswick, A. R. (2001). Using spatial interpolation to construct a comprehensive archive of Australian climate data. Environmental Modelling and Software, 16(4), 309-330. https://doi.org/10.1016/S13648152(01)00008-1.

Jones, G. V. (2003). Winegrape phenology. In M. D. Schwartz (Ed.), Phenology: an integrative environmental science (1st ed., pp. 523-539). Kluwer Press. https://doi.org/10.1007/978-94-007-0632-3_32

Jones, G. V., \& Davis, R. E. (2000). Climate Influences on Grapevine Phenology, Grape Composition, and Wine Production and Quality for Bordeaux, France. American Journal of Enology and Viticulture, 51(3), 249-261. http://www.ajevonline.org/content/51/3/249. abstract

Jones, G. V., Duchêne, E., Tomasi, D., Yuste, J., Braslavska, O., Schultz, H., Martinez, C., Boso, S., Langellier, F., Perruchot, C., \& Guimberteau, G. (2005). Changes in European winegrape phenology and relationships with climate. XIVth International GiESCO Viticulture Congress, 23-27 August 2005, Geisenheim.

Keller, M. (2010). The Science of Grapevines: Anatomy and Physiology. Elsevier Science. http://ebookcentral. proquest.com/lib/unimelb/detail.action?docID $=535176$

Kliewer, W. M., \& Soleimani, A. (1972). Effect of Chilling on Budbreak in 'Thompson Seedless' and 'Carignane' Grapevines. American Journal of Enology and Viticulture, 23(1), 31-34. http://www.ajevonline. org/content $/ 23 / 1 / 31$.abstract

Koufos, G. C., Mavromatis, T., Koundouras, S., \& Jones G, V. (2020). Adaptive capacity of winegrape varieties cultivated in Greece to cliamte change: current trends and future projections. OENO One, 4, 1201-1219. https://doi.org/10.20870/oeno-one.2020.54.4.3129

Lavee, S., \& May, P. (1997). Dormancy of grapevine buds - facts and speculation. Australian Journal of Grape and Wine Research, 3(1), 31-46. https://doi. org/10.1111/j.1755-0238.1997.tb00114.x

Leolini, L., Costafreda-Aumedes, S., Santos, J. A., Menz, C., Fraga, H., Molitor, D., Merante, P., Junk, J., Kartschall, T., Destrac-Irvine, A., van Leeuwen, C., Malheiro, A. C., Eiras-Dias, J., Silvestre, J., Dibari, C., Bindi, M., \& Moriondo, M. (2020). Phenological Model Intercomparison for Estimating Grapevine Budbreak Date (Vitis vinifera L.) in Europe. Applied Sciences, 10(11), 3800. https://doi.org/10.3390/app10113800 
Malheiro, A. C., Campos, R., Fraga, H., Eiras-Dias, J., Silvestre, J., \& Santos, J. A. (2013). Winegrape phenology and temperature relationships in the Lisbon wine region, Portugal. Journal International des Sciences de la Vigne et du Vin, 47, 287-299. https:// doi.org/10.20870/oeno-one.2013.47.4.1558

Martin, S. R., \& Dunn, G. M. (2000). Effect of pruning time and hydrogen cyanamide on budburst and subsequent phenology of Vitis vinifera L. variety Cabernet-Sauvignon in central Victoria. Australian Journal of Grape and Wine Research, 6(1), 31-39. https://doi.org/10.1111/j.1755-0238.2000.tb00159.x

Martinez-Lüscher, J., Kizildeniz, T., Vučetić, V., Dai, Z., Luedeling, E., van Leeuwen, C., Gomès, E., Pascual, I., Irigoyen, J. J., Morales, F., \& Delrot, S. (2016). Sensitivity of Grapevine Phenology to Water Availability, Temperature and $\mathrm{CO}_{2}$ Concentration. Frontiers in Environmental Science, 4(July 12), 1-14. https://doi.org/10.3389/fenvs.2016.00048

Martinez de Toda, F., \& Ramos, M. C. (2019). Variability in grape composition and pheology of 'Tempranillo' in zones located at different elevations and with differences in the climatic conditions. Vitis, $58,131-139$.

Menzel, A., Sparks, T. H., Estrella, N., Koch, E., Aasa, A., Ahas, R., Alm-KÜBler, K., Bissolli, P., BraslavskÁ, O. G., Briede, A., Chmielewski, F. M., Crepinsek, Z., Curnel, Y., Dahl, Å., Defila, C., Donnelly, A., Filella, Y., Jatczak, K., MÅGe, F., Mestre, A., Nordli, Ø., PeÑUelas, J., Pirinen, P., RemiŠOvÁ, V., Scheifinger, H., Striz, M., Susnik, A., Van Vliet, A. J. H., Wielgolaski, F.-E., Zach, S., \& Zust, A. N. A. (2006). European phenological response to climate change matches the warming pattern. Global Change Biology, 12(10), 1969-1976. https://doi. org/10.1111/j.1365-2486.2006.01193.x

Moher, D., Liberati, A., Tetzlaff, J., \& Altman, D. G. (2009). Preferred reporting items for systematic reviews and meta-analyses: The PRISMA statement. Retrieved 12th Jnauary 2021 from http://www.prisma-statement. org/PRISMAStatement/FlowDiagram

Molitor, D., Fraga, H., \& Junk, J. (2020). UniPhen - a unified high resolution model appraoch to simulate the phenological development of a broad range of grape cultivars as well as a potential new bioclimatic indicator. Agricultural and Forest Meteorology, 291, 108024. https://doi.org/10.1016/j.agrformet.2020.108024

Moncur, M. W., Rattigan, K., Mackenzie, D. H., \& McIntyre, G. N. (1989). Base temperatures for budbreak and leaf appearance of grapevines [Article]. American Journal of Enology and Viticulture, 40(1), 21-26.

Morales-Castilla, I., De Cortazar Atauri, I. G., Cook, B. I., Lacombe, T., Parker, A. K., van Leeuwen, C., Nicholas, K. A., \& Wolkovich, E. M. (2020). Diversity buffers winegrowing regions from climate change losses. Proceedings National Academy of Science USA, 117(6), 2864-2869. https://doi.org/10.1073/ pnas. 1906731117
Moran, M. A., Sadras, V. O., \& Petrie, P. R. (2017). Late pruning and carry-over effects on phenology, yield components and berry traits in Shiraz. Australian Journal of Grape \& Wine Research, 23, 390-398. https://doi.org/10.1111/ajgw.12298

Mullins, M. G., Bouquet, A., \& Williams, L. E. (1992). Biology of the Grapevine. Cambridge University Press.

Nendel, C. (2010). Grapevine bud break prediction for cool winter climates. International Journal of Biometeorology, 54(3), 231-241. https://doi. org/10.1007/s00484-009-0274-8

Palliotto, A., Frioni, T., Tombesi, S., Sabbatini, P., Guillermo Cruz-Castillo, J., Lanari, V., Silvestroni, O., Gatti, M., \& Poni, S. (2017). Double-Pruning Grapevines as a Management Tool to Delay Berry Ripening and Control Yield. American Journal of Enology and Viticulture, 68(4), 412-421. https://doi. org/10.5344/ajev.2017.17011

Parker, A. K., De CortÁZar-Atauri, I. G., Van Leeuwen, C., \& Chuine, I. (2011). General phenological model to characterise the timing of flowering and veraison of Vitis vinifera L. Australian Journal of Grape and Wine Research, 17(2), 206-216. https://doi.org/10.1111/j.1755-0238.2011.00140.x

Parker, A. K., Hofmann, R. W., van Leeuwen, C., McLachlan, A. R. G., \& Trought, M. C. T. (2014). Leaf area to fruit mass ratio determines the time of veraison in Sauvignon Blanc and Pinot Noir grapevines. Australian Journal of Grape and Wine Research, 20(3), 422-431. https://doi.org/10.1111/ajgw.12092

Petrie, P. R., Brooke, S. J., Moran, M. A., \& Sadras, V. O. (2017). Pruning after budburst to delay and spread grape maturity. Australian Journal of Grape and Wine Research, 23(3), 378-389. https://doi.org/10.1111/ ajgw.12303

Petrie, P. R., \& Sadras, V. O. (2008). Advancement of grapevine maturity in Australia between 1993 and 2006: putative causes, magnitude of trends and viticultural consequences. Australian Journal of Grape and Wine Research, 14(1), 33-45. https://doi.org/10.1111/j.17550238.2008.00005.x

Ramos, M. C., Jones, G. V., \& Yuste, J. (2015). Spatial and temporal variabiity of cv. Tempranillo phenology and grape quality within the Ribera del Duero (Spain) and relationships with climate. International Journal of Biometeorology, 59, 1849-1860. https://doi. org/10.1007/s00484-015-0992-z

Samish, R. M. (1954). Dormancy in woody plants. Annual Review of Plant Physiology, 5, 183-204. https:// doi.org/10.1146/annurev.pp.05.060154.001151

Schumacher, V., Justino, F., Fernández, A., Meseguer-Ruiz, O., Sarricolea, P., Comin, A., Vanancio, L. P., \& Althoff, D. (2020). Comparison etween observations and gridded data sets over complex terrain in the Chilean Andes: Precipitation and temperature. International Journal of Climatology, 40, 5266-5288. https://doi.org/10.1002/joc.6518 
Schwartz, M. D. (2013). Phenology: An integrative environmental science (M. D. Schwartz, Ed. Second Edition ed.). Springer. https://doi.org/https://doi. org/10.1007/978-94-007-6925-0

Stoll, M., Scheidweiler, M., Lafontaine, M., \& Schultz, H. R. (2011). Possibilities to reduce the velocity of berry maturation through various leaf area to fruit ratio modifications in Vitis vinifera L. Riesling. Progrès Agricoles et Viticole, 127, 68-71.

Tomasi, D., Jones, G. V., Giust, M., Lovat, L., \& Gaiotti, F. (2011). Grapevine Phenology and Climate Change: Relationships and Trends in the Veneto Region of Italy for 1964-2009 [10.5344/ajev.2011.10108]. American Journal of Enology and Viticulture, 62(3), 329. http://www.ajevonline.org/content/62/3/329. abstract

Urhausen, S., Brienen, S., Kapala, A., \& Simmer, C. (2011). Climatic conditions and their impact on viticulture in the Upper Moselle region. Climatic Change, 109, 349-373. https://doi.org/10.1007/s10584011-0059-z

van Leeuwen, C., \& Darriet, P. (2016). The Impact of Climate Change on Viticulture and Wine Quality. Journal of Wine Economics, 11(1), 150-167. https://doi. org/10.1017/jwe.2015.21

van Leeuwen, C., Destrac-Irvine, A., Dubernet, M., Duchêne, E., Gowdy, M., Marguerit, E., Pieri, P.,
Parker, A., L.E., d. R., \& Ollat, N. (2019). An update on the impact of climate change in viticulture and potential adaptations. Agronomy, 9, 1-20. https://doi. org/10.3390/agronomy9090514

Webb, L. B., Whetton, P. H., \& Barlow, E. W. R. (2011). Observed trends in winegrape maturity in Australia. Global Change Biology, 17(8), 2707-2719. https://doi. org/10.1111/j.1365-2486.2011.02434.x

Webb, L. B., Whetton, P. H., Bhend, J., Darbyshire, R., Briggs, P. R., \& Barlow, E. W. R. (2012). Earlier winegrape ripening driven by climatic warming and drying and management practices. Nature Climate Change, 2, 259. https://doi.org/10.1038/nclimate1417

Williams, D. W., Andris, H. L., Beede, R. H., Luvisi, D. A., Norton, M. V. K., \& Williams, L. E. (1985). Validation of a Model for the Growth and Development of the Thompson Seedless Grapevine. II. Phenology. American Journal of Enology and Viticulture, 36(4), 283. http://www.ajevonline.org/ content/36/4/283.abstract

Yonghuo, H. F., Campioli, M., Deckmyn, G., \& Janssens, I. A. (2012). The impact of winter and spring temperatures on temperate tree budburst dates: Results from and experimental climate manipulation. PLoS ONE, 7(10). https://doi.org/doi:10.1371/journal. pone. 0047324 


\section{University Library}

\section{- M M I N E R VA A gateway to Melbourne's research publications}

Minerva Access is the Institutional Repository of The University of Melbourne

Author/s:

Cameron, W;Petrie, PR;Barlow, EWR;Howell, K;Jarvis, C;Fuentes, S

Title:

A comparison of the effect of temperature on grapevine phenology between vineyards

Date:

2021-01-01

Citation:

Cameron, W., Petrie, P. R., Barlow, E. W. R., Howell, K., Jarvis, C. \& Fuentes, S. (2021). A comparison of the effect of temperature on grapevine phenology between vineyards. OENO ONE, 55 (2), https://doi.org/10.20870/oeno-one.2021.55.2.4599.

Persistent Link:

http://hdl.handle.net/11343/281380

License:

CC BY 